\title{
Ophthalmic Timolol and Hospitalization for Symptomatic Bradycardia and Syncope: A Case Series
}

\author{
Syed A. Abbas ${ }^{1,2}$, Syeda M. Hamadani ${ }^{2}$, Umair Ahmad ${ }^{3}$, Aditi Desai ${ }^{1}$, Karishma Kitchloo ${ }^{1}$ \\ 1. Internal Medicine, Montefiore Medical Center/Albert Einstein College of Medicine, Bronx, USA 2. Internal Medicine, \\ Fatima Memorial Hospital College of Medicine and Dentistry, Lahore, PAK 3. Internal Medicine, Ittefaq Trust Hospital, \\ Lahore, PAK
}

Corresponding author: Syed A. Abbas, draliabbas91@gmail.com

\begin{abstract}
Topical beta-blockers are commonly used for the management of primary open angle glaucoma (POAG). One of the rare but serious side effects of the topical beta-blockers is bradycardia, defined as a heart rate below 60 beats per minute. In few cases, the heart rate drops to much lower level resulting in syncope or symptomatic bradycardia. Topical beta-blockers are still widely used for POAG even though there are much better medications available. We present a series of four cases of symptomatic bradycardia resulting from the use of timolol eye drops and after discontinuation of the eye drops, heart rate improved to normal range (60-100 beats per minute).
\end{abstract}

Categories: Cardiology, Internal Medicine, Ophthalmology

Keywords: bradycardia, timolol, primary open angle glaucoma

\section{Introduction}

Glaucoma is defined as an increase in intraocular pressure that can damage the optic nerve. It is the second leading cause of vision loss and its prevalence increases with age [1]. The global prevalence of the disease is estimated to be around 3.54\% according to a meta-analysis report in 2014 [2]. The mainstay treatment of primary open angle glaucoma (POAG) is prostaglandin analog eye drops, but timolol, a non-selective betablocker, is still prescribed which used to be the first-line treatment in the 1980s for lowering intraocular pressure. The drug is used topically but can be systemically absorbed and has the potential of producing serious side effects including bronchospasm, cardiovascular, and central nervous system dysfunction [3-5]. There are a number of studies conducted which establishes association between timolol eye drops and its effect on cardiovascular functions. The cases discussed here emphasize on the importance of deprescribing topical beta-blockers especially in elderly population.

Received 03/04/2020

Review began 03/08/2020 Review ended 03/11/2020 Published 03/14/2020

() Copyright 2020

Abbas et al. This is an open access article distributed under the terms of the Creative Commons Attribution License CC-BY 4.0., which permits unrestricted use, distribution, and reproduction in any medium, provided the original author and source are credited.

\section{Case Presentation \\ Case 1}

An 85 -year-old man presented with a one-day history of profound weakness. He had a past medical history of coronary artery disease, moderate aortic stenosis, hypertension, chronic kidney disease, benign prostatic hyperplasia, and cataracts. His home medications included amlodipine and tamsulosin. A day prior to presentation, he received timolol eye drops at the ophthalmologist's office. In the emergency department (ED), he was found to have a blood pressure (BP) of 70/50 $\mathrm{mmHg}$ and a heart rate (HR) of 49 beats/min, and rest of the physical examination was within normal limit. Electrocardiogram revealed sinus bradycardia at 55 beats/min with first-degree heart block (Figure 1). Old findings of left anterior fascicular block and right bundle branch block can also be seen. He was treated with intravenous (IV) glucagon, to which he promptly responded. Further cardiac workup did not reveal any structural heart abnormalities, and 24-hour telemetry was consistent with sinus bradycardia that improved to normal sinus rhythm after discontinuation of the ophthalmic timolol solution. 


\section{Cureus}

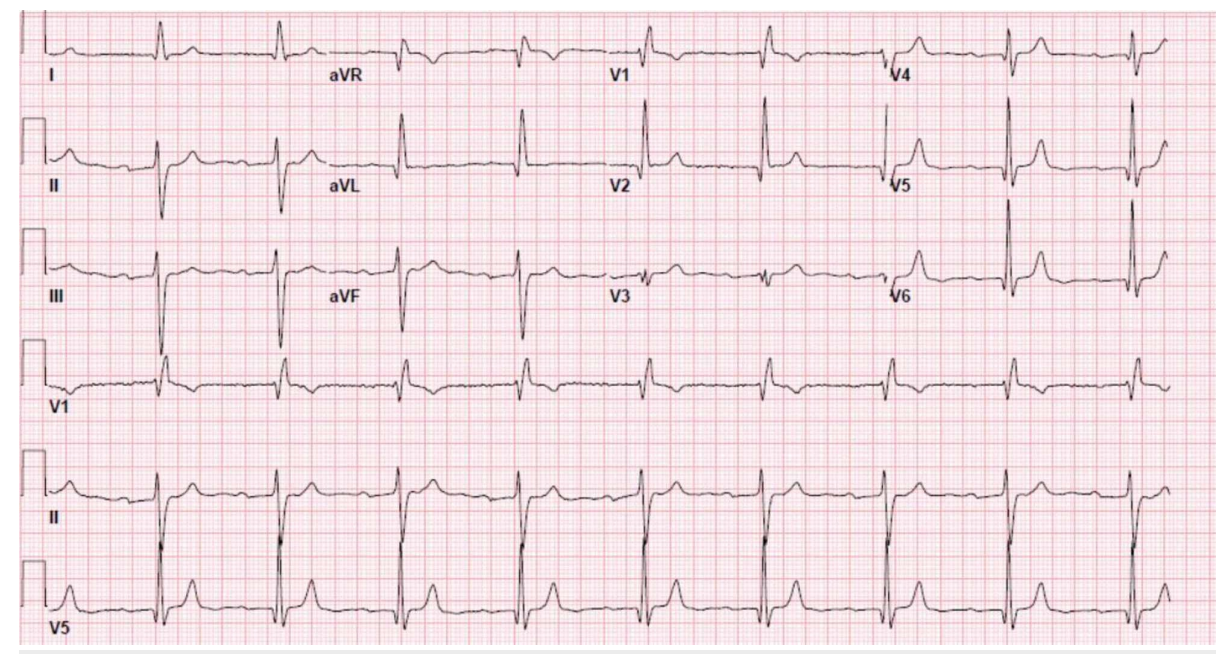

FIGURE 1: Electrocardiogram showing sinus bradycardia and firstdegree atrioventricular block.

\section{Case 2}

A 75-year-old female with past medical history of hypertension, hyperlipidemia, mild dementia, and glaucoma presented with complaint of generalized weakness. Initial BP was 59/33 mmHg, $\mathrm{HR} 61$ beats/min, and finger stick glucose of $93 \mathrm{mg} / \mathrm{dl}$. She was alert, oriented, and no neurological deficit was noted on the physical exam. Basic laboratory workup was unremarkable, and electrocardiogram (EKG) showed sinus bradycardia (Figure 2). Home lisinopril was discontinued, and the patient was given gentle hydration resulting in resolution of symptoms. The patient was discharged home in a medically stable condition. Four days later, she again presented to the ED with similar complaints. At the time of this presentation, her vitals were BP 95/66 mmHg and HR 60 beats/min. Again the blood work and EKG were non-contributory. When asked, the patient and daughter reported onset of symptoms sometimes after instillation of timolol eye drops. Eye drops were held and the patient was discharged home in medically stable condition after normalization of vitals. Follow-up call was done after five days, and the patient reported no recurrence of symptoms with normalization of BP and HR.

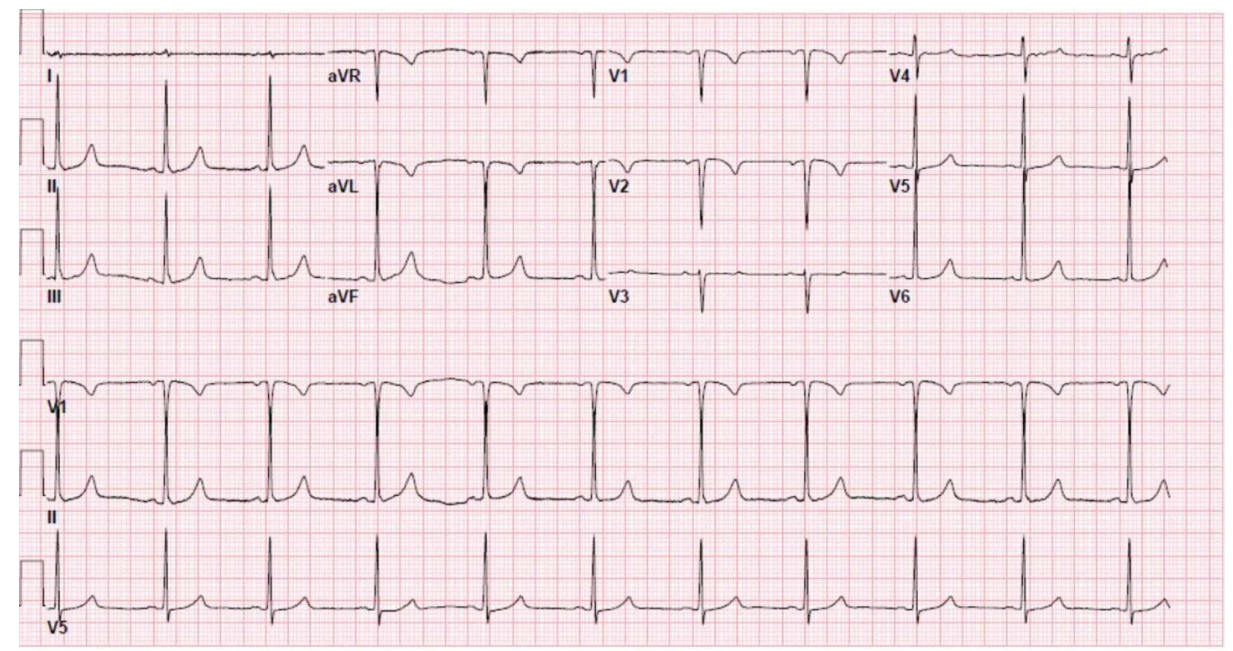

FIGURE 2: Electrocardiogram showing sinus bradycardia.

\section{Case 3}

An 88-year-old female with past medical history of hypertension, hyperlipidemia, glaucoma, and vertigo presented to ED with complaints of lightheadedness, palpitations, and near syncope. Initial vital signs showed BP of 110/70 mmHg and heart rate of 47 beats/min (Figure 3). Telemonitoring was significant for sinus bradycardia. Timolol was held in view of bradycardia, and the patient did not report further episodes of lightheadedness. 


\section{Cureus}

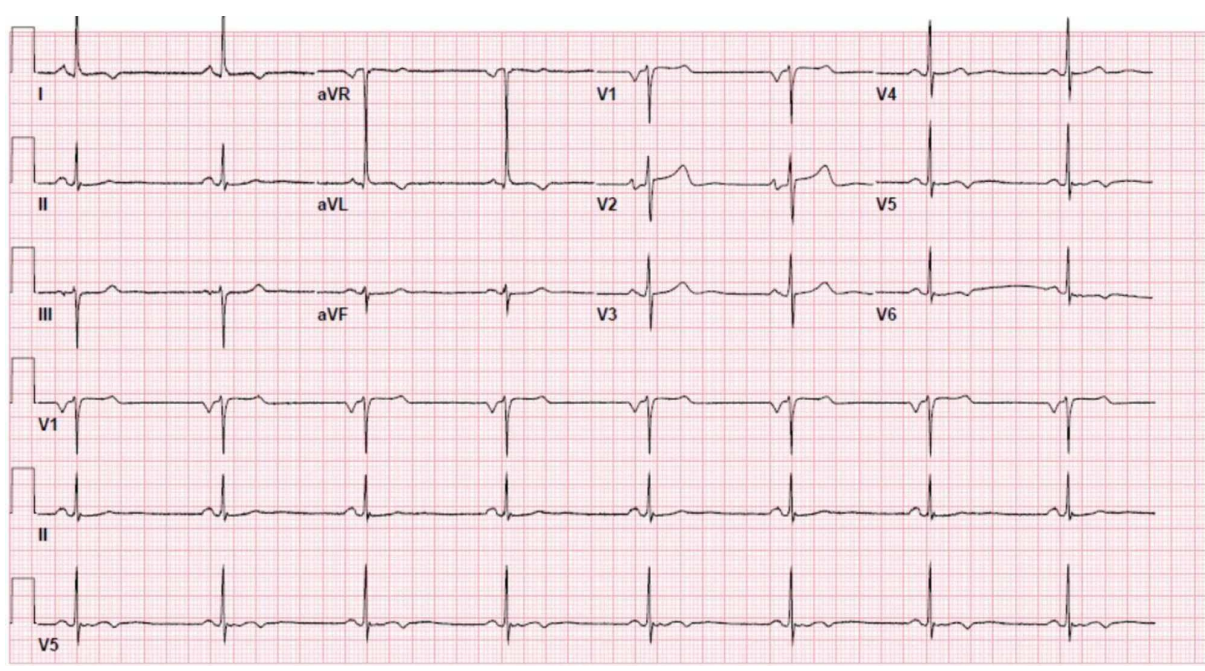

FIGURE 3: Electrocardiogram showing sinus bradycardia.

\section{Case 4}

A 69-year-old female presented to the ED with dizziness for four days and a syncopal episode. In the ED, she was bradycardic ( $45-50$ beats/min) with a BP of $146 / 73 \mathrm{mmHg}$ (Figure 4). Her orthostatic vitals were negative. Physical examination, including a detailed neurological exam, was unremarkable. She received a dose of meclizine in the ED, which showed some improvement in her symptoms but the bradycardia persisted. Her syncope workup was negative, and all cardiogenic andneurogenic causes were ruled out. Further investigation and review of medications revealed timolol eye drops. Holding the eye drops showed significant improvement in her heart rate. Her eye drops were stopped on discharge, and she reported no dizziness episodes on the outpatient follow-up visit.

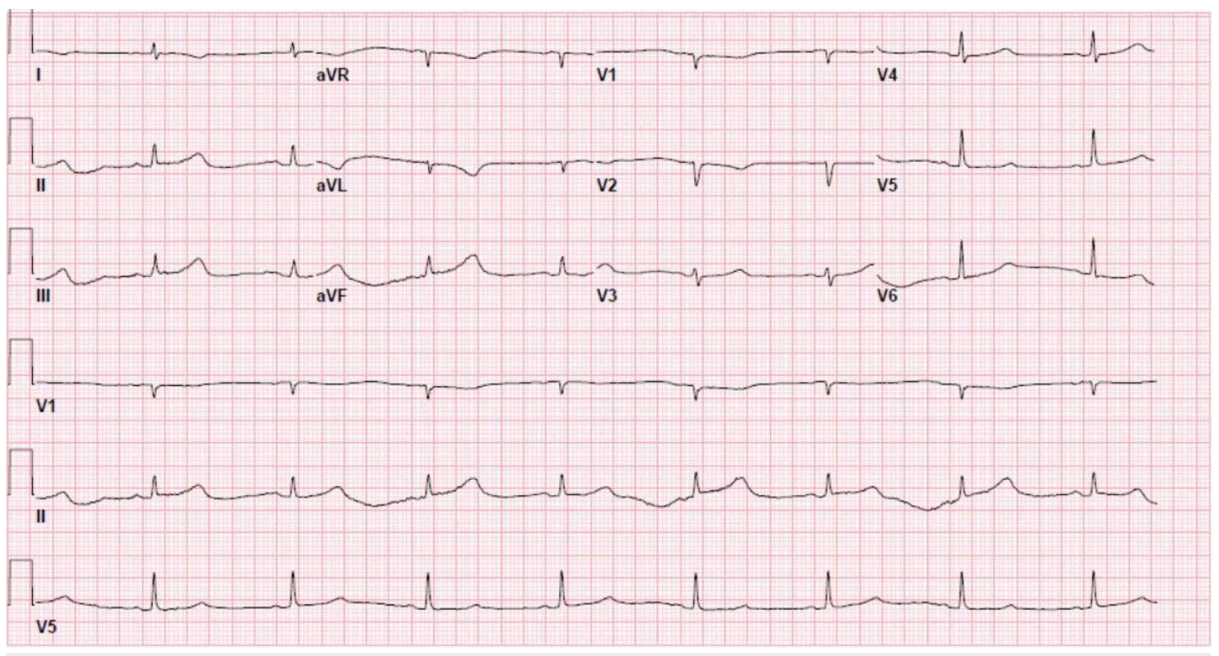

FIGURE 4: Electrocardiogram showing sinus bradycardia.

\section{Discussion}

The estimated prevalence of glaucoma in the US population, aged more than 40 years, is around $2.1 \%$ (approximately 2.9 million individuals) [6]. Approximately $90 \%$ of glaucoma are open angle glaucoma for which topical ophthalmic solutions are prescribed. With the recent advancement in medicine, prostaglandin analog ophthalmic solution is the first-line treatment for POAG. However, before the introduction of prostaglandin analogs, beta-blocker eye drops were the mainstay of treatment.

Timolol, a non-selective beta-blocker, ophthalmic solutions are well known for the management of this condition which is also associated with some serious cardiovascular side effects including bradycardia. The systemic bioavailability, pharmacokinetics, and cardiopulmonary effects of $0.5 \%$ timolol ophthalmic solution are comparable to IV timolol [7]. The systemic bioavailability of ophthalmic timolol is around $78 \%$ compared with oral timolol which is around $61 \%$ due to first pass metabolism, and also the drug was 
detectable in plasma after 15 minutes of administering the ophthalmic solution [7]. Regarding the pharmacokinetics of the $0.5 \%$ ophthalmic timolol, one drop to each eye is estimated to be around $10 \mathrm{mg}$ oral dose $[8,9]$. The half-life of the drug is around four to five hours, and it is metabolized by cytochrome P450 2D6 enzyme (CYP2D6) to inactive metabolites which are excreted by the kidneys [10,11].

Although POAG is more common in elderly population, precautions should be taken in prescribing ophthalmic timolol as the majority of these patients have underlying cardiovascular problems.

The duration of action of the ophthalmic solution is more pronounced and also is more potent in elderly patients as compared to younger ones [12]. There have been reported cases of bradycardia, variable degrees of atrioventricular block, and complete heart blocks with the use of ophthalmic timolol [13-15]. To avoid systemic side effects of the eye drops, gel formulations were developed but the side effects related to betablockade of the receptors were similar in both the groups $[16,17]$.

Even though the first-line treatment for POAG is prostaglandin analogs, we still have many patients in internal medicine clinics and wards who are prescribed non-selective beta-blockers resulting in serious adverse effects. Hence, the clinicians must be aware of the possibility and should consider deprescribing the topical beta-blocker eye drops. Preference should be given to prostaglandin analogs, especially in elderly patients.

\section{Conclusions}

We presented a case series of ophthalmic timolol-induced bradycardia resulting in multiple hospital admission. After ruling out any underlying pathology, the eye drops were discontinued and patients were followed up which showed heart rate improving to normal range. The primary purpose of this case series is to emphasize the side effect profile of non-selective beta-blocker eye drops in elderly population and also change of practice to prescribing prostaglandin analog eye drops, which is now the first-line treatment for POAG.

\section{Additional Information \\ Disclosures}

Human subjects: Consent was obtained by all participants in this study. Conflicts of interest: In compliance with the ICMJE uniform disclosure form, all authors declare the following: Payment/services info: All authors have declared that no financial support was received from any organization for the submitted work. Financial relationships: All authors have declared that they have no financial relationships at present or within the previous three years with any organizations that might have an interest in the submitted work. Other relationships: All authors have declared that there are no other relationships or activities that could appear to have influenced the submitted work.

\section{References}

1. Resnikoff S, Pascolini D, Etya'ale D, et al.: Global data on visual impairment in the year 2002 . Bull World Health Organ. 2004, 82:844-851.

2. Tham YC, Li X, Wong TY, Quigley HA, Aung T, Cheng C-Y: Global prevalence of glaucoma and projections of glaucoma burden through 2040: a systematic review and meta-analysis. Ophthalmology. 2014, 121:20812090. 10.1016/j.ophtha.2014.05.013

3. Everitt DE, Avorn I: Systemic effects of medications used to treat glaucoma . Ann Intern Med. 1990, 112:120125. 10.7326/0003-4819-112-2-120

4. Stewart WC, Castelli WP: Systemic side effects of topical beta-adrenergic blockers . Clin Cardiol. 1996, 19:691-697. 10.1002/clc.4960190904

5. Uusitalo H, Niño J, Tahvanainen K, et al.: Efficacy and systemic side-effects of topical $0.5 \%$ timolol aqueous solution and 0.1\% timolol hydrogel. Acta Ophthalmol Scand. 2005, 83:723-728. 10.1111/j.16000420.2005.00562.x

6. Gupta P, Zhao D, Guallar E, Ko F, Boland MV, Friedman DS: Prevalence of Glaucoma in the United States: The 2005-2008 National Health and Nutrition Examination Survey. Ophthalmol Vis Sci. 2016, 57:2905-2913. 10.1167/iovs.15-18469

7. Korte J-M, Kaila T, Saari KM: Systemic bioavailability and cardiopulmonary effects of $0.5 \%$ timolol eye drops. Graefe's Arch Clin Exp Ophthalmol. 2002, 240:430-435. 10.1007/s00417-002-0462-2

8. Affrime MB, Lowenthal DT, Tobert JA, et al.: Dynamics and kinetics of ophthalmic timolol. Clin Pharmacol Ther. 1980, 27:471-477. 10.1038/clpt.1980.66

9. Alvan G, Calissendorff B, Seideman P, Widmark K., Widmark G: Absorption of ocular timolol . Clin Pharmacokinet. 1980, 5:95-100. 10.2165/00003088-198005010-00004

10. Nieminen T, Uusitalo H, Turjanmaa V, et al.: Association between low plasma levels of ophthalmic timolol and haemodynamics in glaucoma patients. Eur J Clin Pharmacol. 2005, 61:369-374. 10.1007/s00228-0050945-2

11. Nieminen T, Lehtimäki T, Mäenpää J, Ropo A, Uusitalo H, Kähönen M: Ophthalmic timolol: plasma concentration and systemic cardiopulmonary effects. Scand J Clin Lab Inv. 2007, 67:237-245. 10.1080/00365510601034736

12. Vuori ML, Kaila T: Plasma kinetics and antagonist activity of topical ocular timolol in elderly patients . 


\section{Cureus}

Graefes Arch Clin Exp Ophthalmol. 1995, 233:131-4. 10.1007/bf00166604

13. Anguita M, Torres F, Gimenez D, et al.: Bradyarrhythmias secondary to the use of ophthalmic timolol. A report of 3 cases. Rev Esp Cardiol. 1992, 45:71-73.

14. Özcan KS, Güngör B, Osmonov D, et al.: Management and outcome of topical beta-blocker-induced atrioventricular block. Cardiovasc J Afr. 2015, 26:210-213. 10.5830/CVJA-2015-030

15. Sharifi M, Koch JM, Steele RJ, Adler D, Pompili VJ, Sopko J: Third degree AV block due to ophthalmic timolol solution. Int J Cardiol. 2001, 80:257-259. 10.1016/s0167-5273(01)00489-2

16. Ohno Y, Iga T, Yamada Y, Nagahara M, Araie M, Takayanagi R: Pharmacokinetic and pharmacodynamic analysis of systemic effect of topically applied timolol maleate ophthalmic gelling vehicle (Rysmon TG). Curr Eye Res. 2005, 30:319-328. 10.1080/00365510601034736

17. Dickstein K, Hapnes R, Aarsland T: Comparison of aqueous and gellan ophthalmic timolol with placebo on the 24-hour heart rate response in patients on treatment for glaucoma. Am J Ophthalmol. 2001, 132:626632. 10.1016/s0002-9394(01)01181-3 